\title{
Intrathecal Use of Gadobutrol for Glymphatic MR Imaging: Prospective Safety Study of 100 Patients
}

(D) C.S. Edeklev, (D) M. Halvorsen, (D) G. Løvland, (D) S.A.S. Vatnehol, (Dø. Gjertsen, (DB. Nedregaard, DR. Sletteberg, (D) G. Ringstad, and (D)P.K. Eide

\begin{abstract}
BACKGROUND AND PURPOSE: Intrathecal contrast-enhanced glymphatic MR imaging has shown promise in assessing glymphatic function in patients with dementia. The purpose of this study was to determine the safety profile and feasibility of this new MR imaging technique.
\end{abstract}

\begin{abstract}
MATERIALS AND METHODS: A prospective safety and feasibility study was performed in 100 consecutive patients ( 58 women and 42 men, $51 \pm 19$ years of age) undergoing glymphatic MR imaging from September 2015 to August 2018. Short- and long-term serious and nonserious adverse events were registered clinically and by interview after intrathecal administration of $0.5 \mathrm{~mL}$ of gadobutrol (1.0 $\mathrm{mmol} / \mathrm{mL}$ ) along with $3 \mathrm{~mL}$ of iodixanol $(270 \mathrm{mg} \mathrm{l} / \mathrm{mL}$ ). Adverse events are presented as numbers and percentages.

RESULTS: One serious adverse event (anaphylaxis) occurred in a patient with known allergy to iodine-containing contrast agents (1\%). The main nonserious adverse events during the first 1-3 days after contrast injection included severe headache (28\%) and severe nausea (34\%), though the frequency depended heavily on the diagnosis. After 4 weeks, adverse events had resolved.

CONCLUSIONS: Intrathecal administration of gadobutrol in conjunction with iodixanol for glymphatic MR imaging is safe and feasible. We cannot conclude whether short-duration symptoms such as headache and nausea were caused by gadobutrol, iodixanol, the lumbar puncture, or the diagnosis. The safety profile closely resembles that of iodixanol alone.
\end{abstract}

ABBREVIATIONS: gMRI = glymphatic MR imaging; iNPH = idiopathic normal pressure hydrocephalus

$\mathbf{T}$ he glia-lymphatic (or glymphatic) system was described in 2012, providing experimental evidence for direct communication between the CSF of the subarachnoid space and the perivascular spaces of the mouse brain. ${ }^{1}$ The glymphatic pathways were suggested to be dependent on aquaporin- 4 water channels at astrocytic end-feet and are fundamental for the transport and clearance of waste solutes such as amyloid- $\beta$ and $\tau$ protein, which may accumulate in the brain and thereby cause neurodegenerative disease. ${ }^{2}$ Furthermore, it was suggested that intrathecal contrast-enhanced MR imaging might be used for imaging of the glymphatic circulation in man, ${ }^{3,4}$ and such studies have recently

\footnotetext{
Received April 1, 2019; accepted after revision June 15.

From the Department of Neurosurgery (C.S.E., M.H., P.K.E.), Interventional Centre (G.L., S.A.S.V.), and Department of Radiology and Nuclear Medicine (Ø.G., B.N. R.S., G.R.), Oslo University Hospital, Rikshospitalet, Oslo, Norway; and Institute of Clinical Medicine (P.K.E.), Faculty of Medicine, University of Oslo, Oslo, Norway. Camilla S. Edeklev and Merete Halvorsen contributed equally to this work. Please address correspondence to Per Kristian Eide, MD, PhD, Department of Neurosurgery, Oslo University Hospital, Rikshospitalet, Postboks 4950 Nydalen, 0424 Oslo, Norway; e-mail: p.k.eide@medisin.uio.no

http://dx.doi.org/10.3174/ajnr.A6136
}

confirmed communication between the subarachnoid space and the extravascular compartment of all brain regions, thereby extending previous animal data (Fig 1).

The human glymphatic system differs from that in rodents in several ways, first by being much slower. ${ }^{5,6}$ Moreover, human studies have shown delayed clearance of CSF tracer from all brain regions in individuals with idiopathic normal pressure hydrocephalus (iNPH), ${ }^{5}$ and particularly from the entorhinal cortex, where volume loss precedes hippocampal atrophy in Alzheimer disease. ${ }^{7}$ After the discovery of meningeal brain lymphatic vessels in 2015, ${ }^{8,9}$ observations from human glymphatic MR imaging (gMRI) have suggested a functional link between glymphatic and lymphatic pathways because peak CSF tracer enhancement coincided in time in both the brain and extracranial lymph nodes. ${ }^{10}$

The risk of gadolinium retention within the human brain after repeat intravenous administrations has been extensively debated. ${ }^{11-13}$ It has recently been acknowledged that gadoliniumcontaining MR imaging contrast agents leak from blood to the CSF, ${ }^{14}$ even in patients without blood-brain barrier dysfunction, ${ }^{15}$ and probably in substantial amounts through the choroid plexus. ${ }^{16}$ In principle, an intravenous dosage of contrast agent to 


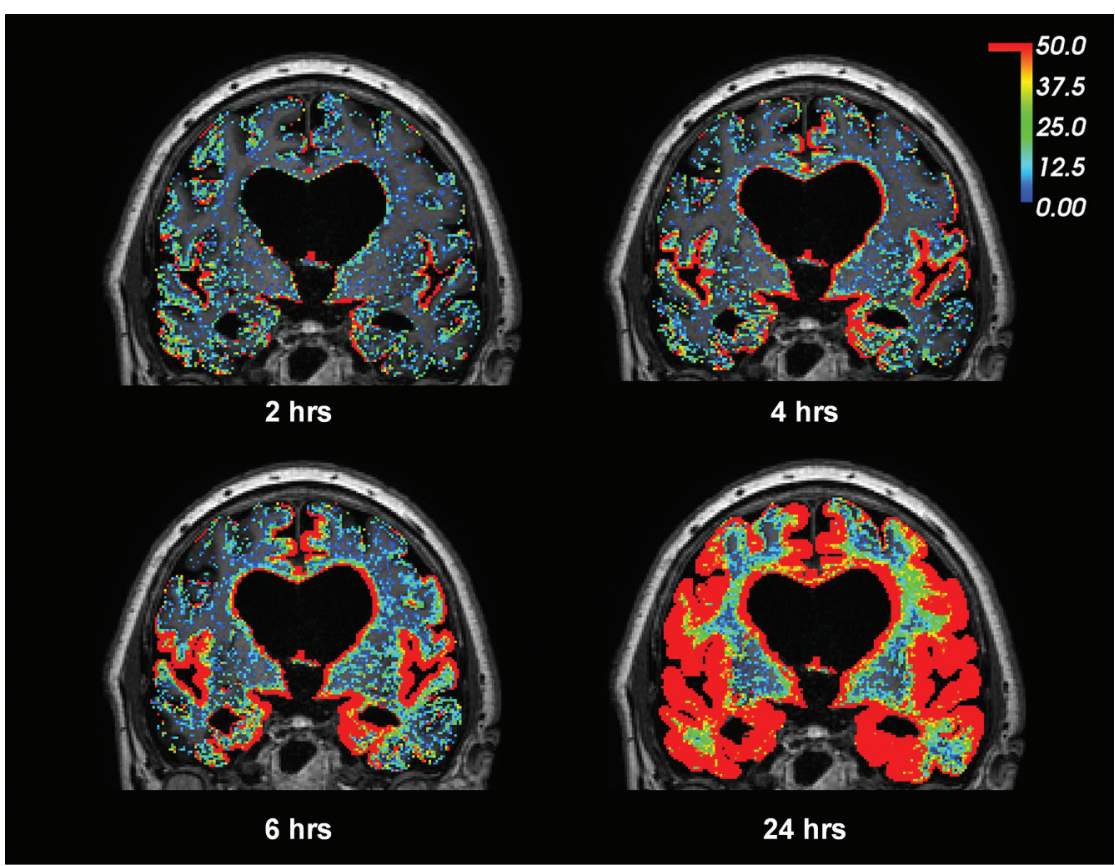

FIG 1. gMRI in a subject with iNPH. Intrathecal gadobutrol $(0.05 \mathrm{mmol})$ used as a CSF tracer, followed by MR imaging acquisitions after 2, 4, 6, and 24 hours, shows enrichment of the CSF tracer as a percentage change in the $\mathrm{Tl}$ signal unit ratio. The color scale shows a contrast agentdependent percentage increase in the $\mathrm{Tl}$ signal unit ratio (for more detailed description see Ringstad et $\left.\mathrm{al}^{5}\right)$. Note that contrast enhancement of the brain occurred in a centripetal pattern and primarily in regions of the brain adjacent to large artery trunks at the surface-that is, the anterior, middle, and posterior cerebral arteries. The periventricular tracer enhancement is due to reflux of tracer into the ventricular system, which is a typical feature of iNPH.

\section{MR Imaging Protocol}

Sagittal T1-weighted spoiled gradientecho volume scans were obtained using a 3T Ingenia MR imaging scanner (Philips Healthcare, Best, the Netherlands), with equal imaging sequence parameters at all time points. The main imaging parameters were the following: $\mathrm{TR}=$ shortest (typically $5.1 \mathrm{~ms}$ ), $\mathrm{TE}=$ shortest (typically $2.3 \mathrm{~ms}$ ), flip angle $=8^{\circ}, \mathrm{FOV}=256 \times 256 \mathrm{~cm}$, matrix $=256 \times 256$ pixels (reconstructed to $512 \times 512$ ). We sampled 184 overcontiguous slices with 1-mm thickness that were automatically reconstructed to 368 slices with a thickness of $0.5 \mathrm{~mm}$. Each image acquisition lasted 6 minutes 29 seconds.

\section{Intrathecal Administration of Gadobutrol}

After precontrast MR imaging (approximately $8 \mathrm{AM}$ ), the patient was transported on a mobile table to an adjacent neurosurgery operating room, where an interventional neuroradiologist performed x-ray-guided lumbar puncture. The level that provided the best access to the spinal canal was determined by the venous blood therefore also represents a dosage of contrast agent to the CSF.

With this background, exploring the safety profile of intrathecal MR imaging contrast agent administration is highly warranted. We performed a prospective safety and feasibility study of 100 individuals undergoing gMRI following intrathecal injection of $0.5 \mathrm{~mL}$ of gadobutrol (Gadovist, $1.0 \mathrm{mmol} / \mathrm{mL}$; Bayer Schering Pharma, Berlin, Germany), in conjunction with $3 \mathrm{~mL}$ of iodixanol (Visipaque, 270 mg I/mL; GE Healthcare, Piscataway, New Jersey), and recorded immediate, short-term, and long-term adverse events.

\section{MATERIALS AND METHODS \\ Approvals}

The institutional review board (2015/1868), regional ethics committee (2015/96), and the National Medicines Agency (15/ 04932-7) approved the study. Inclusion was by written and oral informed consent.

\section{Experimental Design and Patients}

This observational and prospective study included consecutive patients admitted to the Department of Neurosurgery, Oslo University Hospital, Rikshospitalet, for management of tentative CSF circulation disorders during September 2015 to August 2018 (Table 1).

We used the following exclusion criteria: history of hypersensitivity reactions to contrast agents, history of severe allergy reactions in general, evidence of renal dysfunction, pregnant or breastfeeding women, and age younger than 18 years or older than 80 years. neuroradiologist on an individual basis, most typically at level L2/L3 or L3/L4, and, in some cases, at level L4/5. Correct placement of a spinal syringe tip in the subarachnoid space at the lower lumbar level was verified in terms of CSF backflow from the puncture needle (22 ga $\times 3.5$ inches). Subsequently, a mixture of 2-3 $\mathrm{mL}$ of $270 \mathrm{mg} \mathrm{I} / \mathrm{mL}$ of iodixanol (Visipaque) and $0.5 \mathrm{~mL}$ of 1.0 $\mathrm{mmol} / \mathrm{mL}$ gadobutrol (Gadovist) was injected guided by fluoroscopy, to confirm unrestricted distribution of radiopaque contrast agent in the lumbar subarachnoid space. After needle removal, the patients were instructed to rotate around the long axis of the body once before transportation back to the MR imaging suite, to keep the patient in the supine position.

\section{Postcontrast MR Imaging Acquisitions and Image Analysis}

Assessment of contrast agent entry at the level of the craniocervical junction (spinal transit time) by means of MR imaging was initiated as soon as possible after intrathecal gadobutrol administration (typically with an approximately 5- to 10-minute delay). Consecutive and identical MR imaging acquisitions covering the cranial compartment and upper neck region with the previously outlined MR imaging protocol parameters were initiated and performed approximately every 10 minutes during the first hour after contrast agent injection. The patients were thereafter instructed to remain supine in bed. Repeat, identical MR imaging acquisitions were then performed approximately every 2 hours after intrathecal gadobutrol administration until afternoon (about 4 PM). Transfer of patients between the neurosurgical department and the MR imaging suite and between the bed and the MR imaging table was performed by the hospital staff to help the 


\begin{tabular}{lc}
\hline & Total Material \\
\hline No. & 100 \\
Mean age (yr) & $51 \pm 19$ \\
Sex (female/male) & $58: 42$ \\
BMI (kg/m $\left.{ }^{2}\right)$ & $27 \pm 5$ \\
Comorbidity & \\
$\quad$ Hypertension & $18(18 \%)$ \\
$\quad$ Diabetes & $4(4 \%)$ \\
Diagnosis & \\
iNPH & $35(35 \%)$ \\
SIH & $14(14 \%)$ \\
AC & $18(18 \%)$ \\
PC & $22(22 \%)$ \\
IIH & $6(6 \%)$ \\
CHC & $5(5 \%)$ \\
\hline
\end{tabular}

Note:-SIH indicates spontaneous intracranial hypotension; AC, arachnoid cyst; PC, pineal cyst; IIH, idiopathic intracranial hypertension; $\mathrm{CHC}$, communicating hydrocephalus; BMI, body mass index.

${ }^{a}$ Data are No. (percentage in parentheses) and means.

patient remain in the supine position. Beginning in the afternoon, the patients could move freely; new MR imaging acquisitions were repeated after 24 and 48 hours.

The first appearance of any MR imaging contrast agent at the level of the foramen magnum was assessed visually by an experienced neuroradiologist (G.R.) on the sagittal T1-weighted volume scans in the hospital PACS.

\section{Assessment of Serious and Nonserious Adverse Events}

Serious and nonserious adverse events were recorded systematically by study nurses not otherwise involved in management of patients. Serious adverse events were defined as any untoward medical occurrence that, at any dose, results in the following: death, an immediately life-threatening situation, inpatient hospitalization or prolongation of existing hospitalization, persistent or significant disability or incapacity, or an important medical event that may jeopardize the subject or may require medical intervention to prevent one of the outcomes listed here. Adverse events not having these consequences were considered nonserious.

Assessment of adverse events was performed prospectively during days 1-3 after intrathecal contrast agent administration, after 4 weeks, and finally after about 12 months. The patients were specifically queried for the presence of a defined set of symptoms presenting or being aggravated after intrathecal contrast administration and MR imaging and for symptom duration. These symptoms were chosen according to adverse effects most commonly observed after intrathecal iohexanol: headache (mild/ moderate/severe), nausea (mild/moderate/severe), dizziness (mild/moderate/severe), itch, warm feeling, paresthesia, visual problems, cognitive difficulties, muscular spasms, discomfort at the injection site, and tremor. Other symptoms than those specifically requested were listed independent of possible causes. All patients who still reported symptoms at 4 weeks were phoned by the study nurses at a later time, ranging from a few months to up to 12 months, for a final assessment. Report of symptoms at any other contact after 4 weeks was also registered and categorized as "late."

\section{RESULTS}

\section{Patients}

Table 1 presents demographic information about the 100 consecutive patients who were included in the study. The cohort included 58 female and 42 male patients, with a mean of $51 \pm 19$ years of age. Comorbidity was common.

\section{Verified Intracranial Distribution of Gadobutrol}

Gadobutrol enhancement in cranial CSF spaces was verified in all individuals (Fig 2). Contrast was still visible intracranially after 24 and 48 hours. The gMRI of 1 patient with iNPH is shown in Fig 3.

The mean time from intrathecal administration of gadobutrol until the first visual detection of the contrast agent at the foramen magnum (spinal transit time) was $20 \pm 23$ minutes (median, 13 minutes; range, 6-150 minutes). As illustrated in Fig 4, there was some interindividual variation concerning spinal transit time. There were no significant differences in spinal transit time across the patient groups (data not shown). In all patients, scans obtained until 4 PM were assessed visually to ensure the expected magnitude of enhancement in the intracranial CSF spaces, which could be confirmed. Prolonged spinal transit time was, therefore, less likely to be attributed to extradural injection of contrast agent at the lumbar level.

\section{Serious Adverse Effects}

No patients without a history of prior adverse events experienced serious adverse reactions likely related to intrathecal gadobutrol administration. One woman with established allergy to iodinated radiocontrast agents was, by error, included in the study, even after interaction with the referring doctor, study nurse, the neurologist who managed hospital admittance, and an anesthesiologist. This individual experienced an immediate anaphylactic reaction consisting of skin rash, dyspnea, and a fall in blood pressure, symptoms that were comparable with a previous reaction to iodinated radiocontrast agent (Table 2). Fortunately, after receiving intravenous Ringer-acetate $(1000 \mathrm{~mL})$ and surveillance within the intensive care unit for a few hours, no further actions were required. After a few hours, the patient was able to undergo MR imaging, though estimation of spinal transit time was not possible in this individual.

One 80-year-old man with iNPH had a pulmonary embolism, which was attributed to a long train journey and reduced mobility a few days before.

\section{Nonserious Adverse Events}

The nonserious adverse events within 3 days, at 4 weeks, and at 12 months, respectively, are presented in Table 2.

Nonserious adverse events within the first 1-3 days (delayed) after intrathecal gadobutrol were rather frequent and usually occurred after 10-20 minutes or in the afternoon about 3 PM. Adverse events rarely occurred at days 2 or 3 . Twenty-two of 100 individuals reported no symptoms, while 78/100 individuals had symptoms of variable degrees (Table 2). About one-third of individuals experienced the combination of severe headache and nausea. These symptoms were managed conservatively. Whether the high frequency of headache and nausea was caused by the under- 


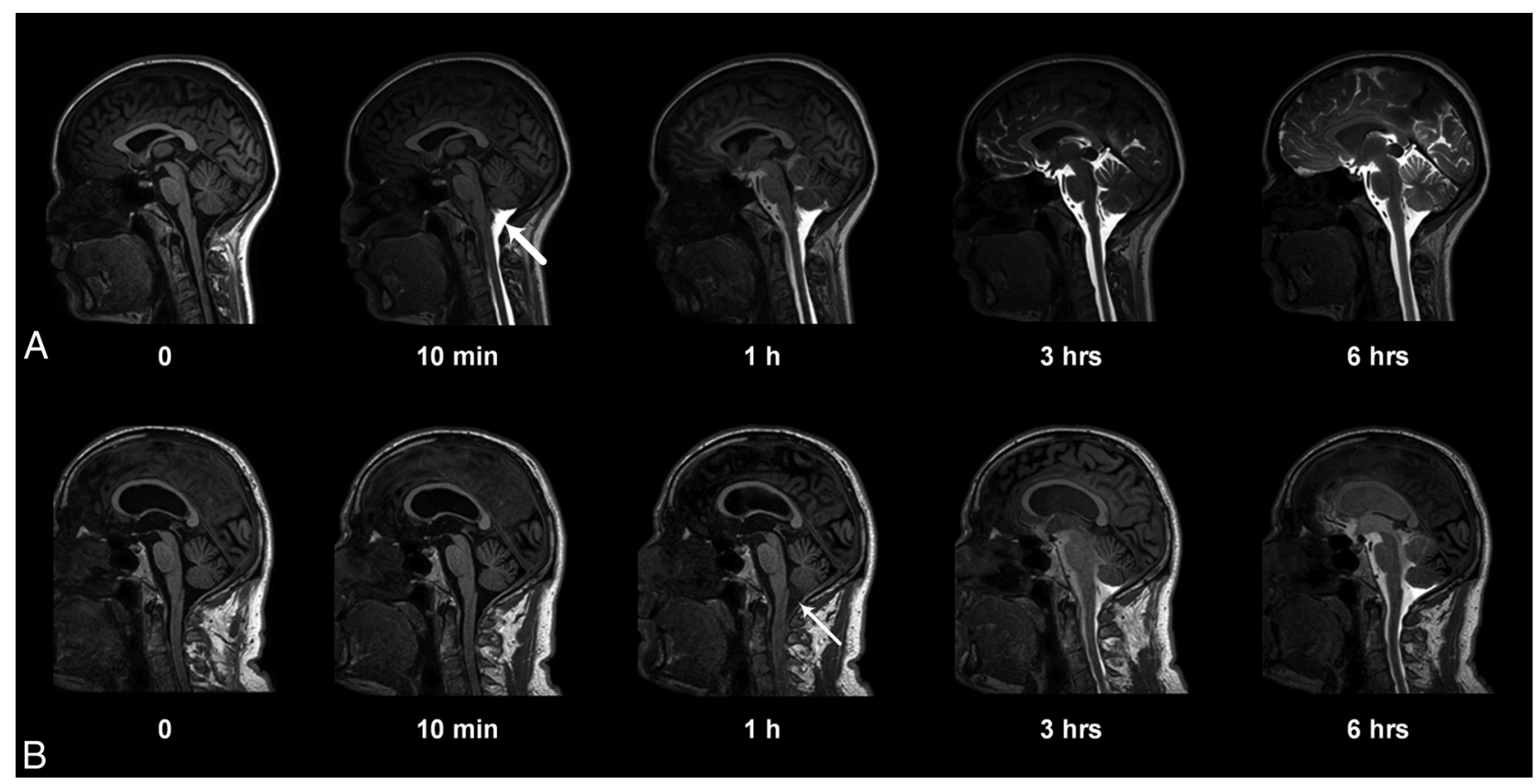

FIG 2. Entry of gadobutrol into the CSF within the intracranial compartment at consecutive MR imaging of a patient with a pineal gland cyst $(A)$ and $\mathrm{iNPH}(B)$. Intrathecal administration of $0.5 \mathrm{~mL}(1.0 \mathrm{mmol} / \mathrm{mL})$ of gadobutrol at the lower lumbar level was preceded by unenhanced, T1-weighted MR imaging (time point zero). After the correct needle position had been verified at fluoroscopy by injection of $3 \mathrm{~mL}$ of iohexanol $(270 \mathrm{mg} \mathrm{l} / \mathrm{mL}$ ), the patient was transported in the supine position to the MR imaging suite next door, and acquisition of identical, consecutive T1 scans was initiated immediately and performed continuously within the first hour. Typically, the contrast agent had reached the cisterna magna at the first postcontrast scan obtained after approximately 10 minutes ( $A$, thick arrow). In some patients, however, enhancement occurred much later, as in $B$, where slight enhancement was first depicted at 1 hour (thin arrow). At 6-hour scans, gadobutrol is distributed widely in the CSF of both patients, but less prominently in $B$, where ventricular reflux can also be noted.

lying disease, the gadobutrol or iohexanol per se, or the spinal puncture could not be determined with certainty.

After 4 weeks, 88 individuals reported no symptoms, while 12 had various symptoms (Table 2). One individual with iNPH reported an itch. In 5 patients with either pineal or arachnoid cysts, 3 had variable degrees of headache, 1 had nausea, and 1 reported dizziness. Three patients reported discomfort at the injection site or in the lumbar region and/or paresthesia, which most likely was related to the lumbar puncture itself.

After 12 months, 1 patient with a pineal cyst had mild headache and dizziness, but these symptoms were the same as she experienced before MR imaging (Table 2).

Table 3 presents nonserious adverse events recorded during days $1-3$ according to the diagnosis category. The data show that symptoms like headache, nausea, and dizziness particularly depend on the diagnosis. For example, 15/22 (68\%) patients with pineal cysts reported severe headache and nausea, while severe headache and nausea were reported by $2 / 35$ (6\%) and 10/35 (29\%) patients with iNPH, respectively. Moreover, while no symptoms were reported by $12 / 35$ (34\%) patients with $\mathrm{iNPH}$, they were reported by $0 / 22(0 \%)$ patients with pineal cysts. Notably, the high frequency of symptoms such as headache, nausea, and dizziness reported by patients with pineal gland cysts closely resembles the frequency and character of symptoms they had experienced previously and that represented the main reason for their referral to our hospital in the first place.

\section{DISCUSSION}

The main observation of this prospective study is that administration of $0.5 \mathrm{~mL}$ of gadobutrol $(1.0 \mathrm{mmol} / \mathrm{mL})$ is safe in patients with no history of allergic reactions to contrast agents.

Nonserious adverse events were rather frequent; however, the occurrence depended heavily on the diagnosis. Among individuals with a pineal cyst, 15/22 (68\%) reported severe headache and nausea during days $1-3$. We previously reported a high frequency of these symptoms in this patient group in general. ${ }^{17}$ Headache is a predominant symptom in individuals with symptomatic arachnoid cysts. ${ }^{18}$ We cannot with certainty know whether nonserious adverse events such as headache, nausea, and dizziness after 1-3 days or after 4 weeks were caused by any of the contrast agents or related to the diagnosis itself. Inclusion of other patient categories, such as those with iNPH, most likely would provide other frequencies of reported symptoms.

Because gadobutrol was given in conjunction with iohexanol, to what extent these adverse effects can be attributed to gadobutrol alone remains unanswered.

The study reports prospective data from 100 patients to whom intrathecal gadobutrol was given off-label after special permission from the National Medicines Agency of Norway. Intrathecal doses of MR imaging contrast agents in similar amounts have, however, been used off-label on a clinical basis for years to visualize CSF leakage in individuals with spontaneous intracranial hypotension, as previously reported by others. ${ }^{19,20}$ Intrathecal MR imaging contrast agents were also found to benefit assessment 


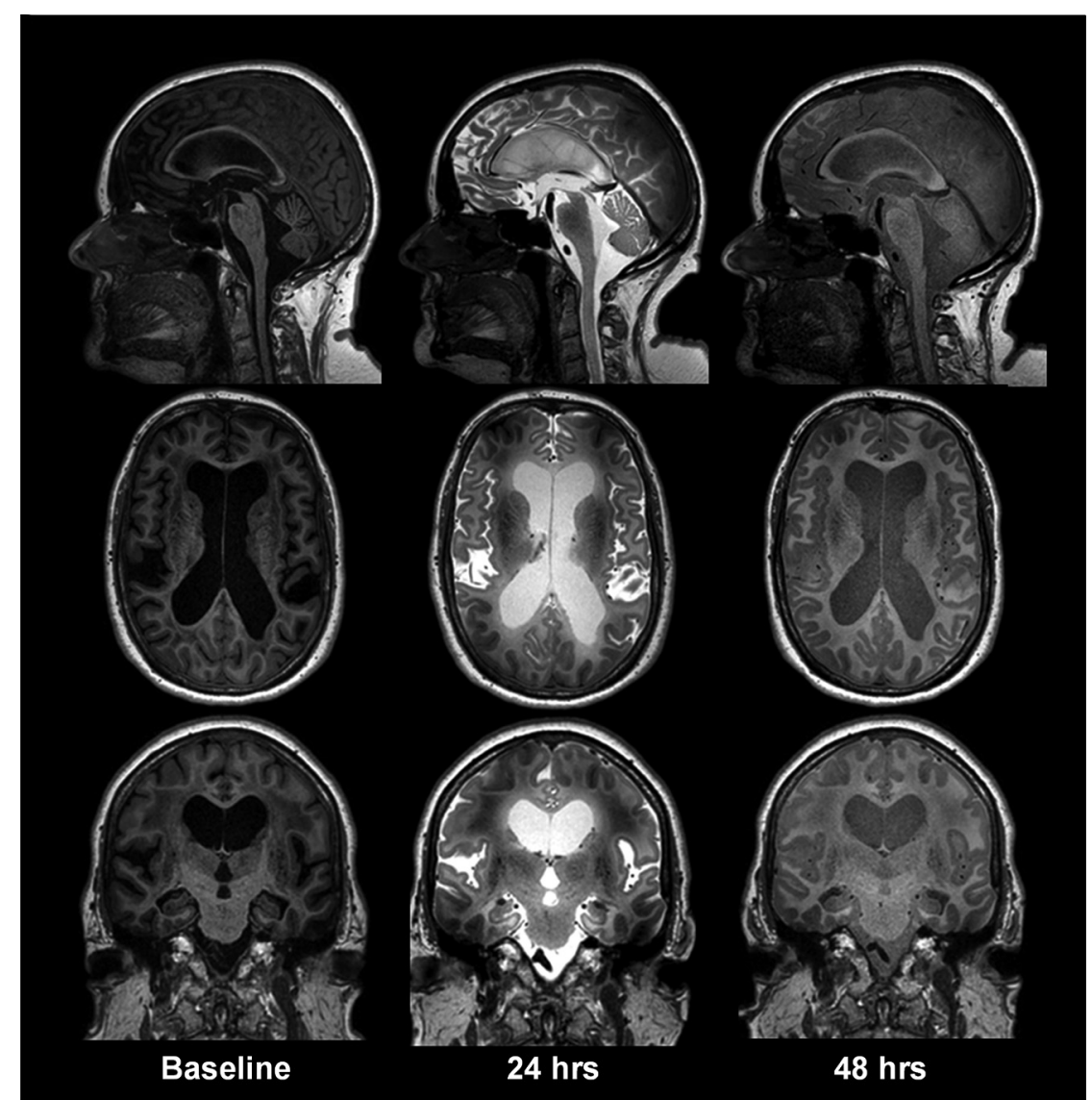

FIG 3. gMRI shown as standardized $T 1$ acquisitions before and 24 and 48 hours after intrathecal gadobutrol in a subject with iNPH, including midsagittal, midaxial, and midcoronal images. In iNPH, gadobutrol clearance from the CSF is delayed compared with reference patients at 24 and 48 hours, respectively. Other typical features of iNPH are early ventricular reflux and subsequent periventricular enhancement of contrast agent, typically most prominent at 24 hours.

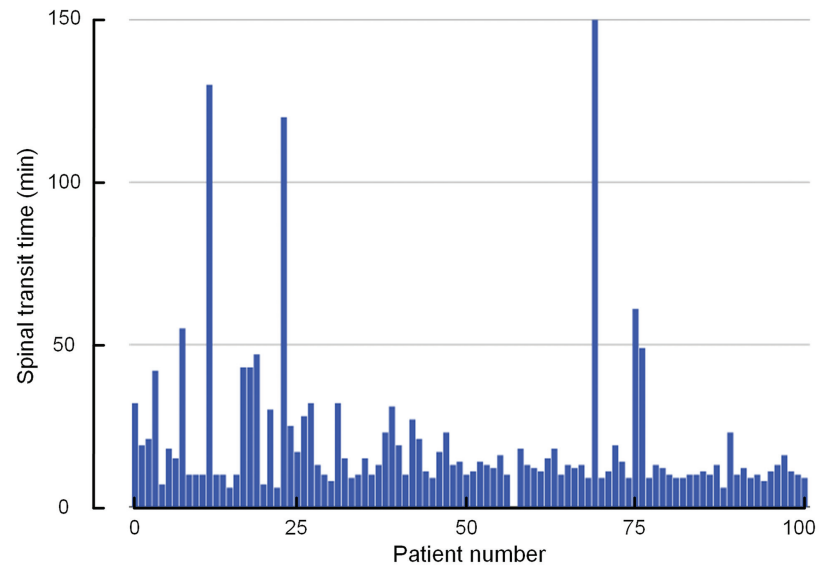

FIG 4. The time from intrathecal administration of gadobutrol until the first enhancement of the contrast agent within subarachnoid space of the foramen magnum (spinal transit time) for the 100 patients included in the study. The mean \pm SD spinal transit time was $20 \pm 23$ minutes.

of arachnoid cysts ${ }^{21}$ and $\mathrm{iNPH},{ }^{22}$ and in diagnosing the cause of otorhinorrhea. $^{23}$

We verified that gadobutrol reached the intracranial CSF compartment in all subjects (except the one with an anaphylactic reaction). The mean spinal transit time was $20 \pm 23$ minutes (median, 13 minutes; range, 6-150 minutes; Fig 4).
In terms of safety with intrathecal gadolinium injections, the linear contrast agents have been more investigated than the macrocyclic ones. Gadopentetic acid in a dose $0.5-1.0 \mathrm{mmol}$ was well-tolerated in animal studies $^{20,21,24-27}$ and was found to have a low risk when given in low doses (0.5-1.0 mmol) to patients. ${ }^{19,24-26,28,29}$ Headache has been the most dominating adverse effect, which also might be related to the spinal puncture. Neurotoxic effects on animal brains were seen when gadopentetic acid was given intraventricularly in a dose of $5.0 \mu \mathrm{mol} / \mathrm{g}$ brain but was not observed when the dose was $<3.3-\mu \mathrm{mol} / \mathrm{g}$ brain. ${ }^{30}$ Previous studies in patients showed that overdose of gadopentetic acid (6-20 times the normal dose) can be neurotoxic. ${ }^{31,32}$ Hence, 1 patient who, by accident, received 20 $\mathrm{mL}$ of gadopentetic acid $(7.0 \mu \mathrm{mol} / \mathrm{g}$ brain) developed neurologic deficits (speech problems, visual impairment, fatigue, and psychotic symptoms) lasting 2 weeks, but symptoms had disappeared after 2 months. ${ }^{33}$ Moreover, following intrathecal administration of 2.0 $\mathrm{mL}$ of gadobutrol, 1 individual reported spastic pain of the lower extremities. ${ }^{34}$

In an adult brain weighing $1400 \mathrm{~g}$, gadobutrol in a dose of $0.5 \mathrm{mmol}$ corresponds to $500-\mu \mathrm{mol} / 1400-\mathrm{g}$ brain $(0.36-\mu \mathrm{mol} / \mathrm{g}$ brain). Thus, the dose of gadobutrol in this study was on the order of one-tenth of previously appreciated toxic levels. Nevertheless, nonserious adverse events within 1-3 days postcontrast were seen rather frequently, in particular headache and nausea. Intrathecal gadopentetic acid was previously reported to cause headache in $10 / 36(27 \%)$ patients with $\mathrm{NPH}^{22}$ and in $6 / 20(30 \%)$ patients with arachnoid cysts. ${ }^{29}$

Iodixanol was given intrathecally to verify the correct needle position, which is part of the spinal puncture routine. The safety profile of iodixanol ${ }^{35}$ closely resembles that of gadobutrol in combination with iodixanol in this current study. Thus, intrathecal iodixanol caused nonserious adverse events in a comparable proportion of patients as reported here. ${ }^{35}$

While MR imaging contrast agents are approved for intravenous administration only, gadolinium has recently been depicted in CSF samples obtained from individuals even with normal renal function and an intact blood-brain barrier. ${ }^{14,15}$ Given that the concentration of MR imaging contrast agent in CSF exceeded that of blood 4.5 hours after intravenous administration, ${ }^{16}$ a typical intravenous dose $(0.1 \mathrm{mmol} / \mathrm{kg}$ in a $80-\mathrm{kg}$ patient $=8 \mathrm{mmol}$, half-time in blood is approximately 2 hours) may cause significant passage of contrast agent to the CSF. Except from our previous reports using gMRI, ${ }^{5-7,10}$ time-dependent quantification of gadobutrol in human CSF after a typical intravenous dose, for 
example using T1 maps, has been reported in a case study. ${ }^{36}$ Four weeks after 1 single intrathecal administration, gadolinium is not detectable by MR imaging in any brain region, including the basal ganglia. ${ }^{5}$

The potential risk inherent in the use of any contrast agent should always be weighed against its potential benefits. After intrathecal contrast-enhanced MR imaging of humans was first proposed, ${ }^{3,4}$ gMRI has been demonstrated to be a promising clinical tool in the assessment of CSF circulation disorders. ${ }^{5-7}$ In particular, delayed glymphatic clearance of gadobutrol, which is anticipated to be cleared through the same pathways as amyloid- $\beta$ and $\tau$, has been proved in a dementia cohort. ${ }^{5}$ Contrast enhancement of the entire brain extravascular space is expected to have a large potential for better characterization of disease within the brain and spinal cord but remains yet unexplored.

\section{Limitations}

While the present study addressed the safety profile of intrathecal gadobutrol, the major limitation is that we cannot determine with certainty which adverse events solely relate to the MR imaging contrast agent. The nonserious effects we observed might, as well, be caused by the accompanied administration of iodixanol, the spinal puncture, a heavy load of repeat MR imaging, and repeat transport to and from the MR imaging lab.

To what extent the nonserious adverse events are related to the dose of intrathecal gadobutrol remains to be determined. Another study ${ }^{23}$ using 0.5 $\mathrm{mL}$ of Gd-DTPA or Magnevist (Bayer HealthCare Pharmaceuticals, Wayne, New Jersey), which corresponds to half the dose of gadobutrol used in the present study, seemed to give a better profile concerning nonserious adverse events, though having a high sensitivity in diagnosing the cause of otorhinorrhea. Hence, a lower dose of gadobutrol than used in the present study might give fewer adverse effects. However, because gadobutrol distributes to both the CSF and the entire extravascular compartment, it remains to be determined whether such low doses are sufficient to demonstrate contrast enhancement in deep brain regions, where we have experienced it to be quite marginal. ${ }^{5}$ In fu-

${ }^{a}$ Data are No. of individuals (percentage in parentheses).

Table 3: Occurrence of nonserious adverse events within days 1-3, depending on diagnosis ${ }^{a}$

\begin{tabular}{|c|c|c|c|c|c|c|}
\hline Nonserious Adverse Events & iNPH $(n=35)$ & $\operatorname{SIH}(n=14)$ & $\mathrm{AC}(n=18)$ & $\mathrm{PC}(n=22)$ & $\mathrm{IIH}(n=6)$ & $\mathrm{cHC}(n=5)$ \\
\hline \multicolumn{7}{|l|}{ Headache } \\
\hline Mild & $1(3 \%)$ & $2(14 \%)$ & 0 & 0 & 0 & 0 \\
\hline Moderate & $2(6 \%)$ & $3(21 \%)$ & $2(11 \%)$ & $4(18 \%)$ & 0 & $2(40 \%)$ \\
\hline Severe & $2(6 \%)$ & $2(14 \%)$ & $6(33 \%)$ & $15(68 \%)$ & $1(17 \%)$ & $2(40 \%)$ \\
\hline \multicolumn{7}{|l|}{ Nausea } \\
\hline Mild & $6(17 \%)$ & $2(14 \%)$ & $4(22 \%)$ & $4(18 \%)$ & 0 & $2(40 \%)$ \\
\hline Moderate & $1(3 \%)$ & $1(7 \%)$ & $1(6 \%)$ & $1(5 \%)$ & $1(17 \%)$ & 0 \\
\hline Severe & $10(29 \%)$ & $2(14 \%)$ & $5(28 \%)$ & $15(68 \%)$ & $1(17 \%)$ & $1(20 \%)$ \\
\hline \multicolumn{7}{|l|}{ Dizziness } \\
\hline Mild & $4(11 \%)$ & $2(14 \%)$ & $2(11 \%)$ & $2(9 \%)$ & 0 & 0 \\
\hline Moderate & $1(3 \%)$ & $1(7 \%)$ & $3(17 \%)$ & $6(27 \%)$ & 0 & 0 \\
\hline Severe & 0 & 0 & $5(28 \%)$ & $9(41 \%)$ & $2(33 \%)$ & $1(20 \%)$ \\
\hline Itch & $1(3 \%)$ & 0 & $1(6 \%)$ & 0 & 0 & $1(20 \%)$ \\
\hline Warm feeling & $3(9 \%)$ & $1(7 \%)$ & $1(6 \%)$ & $2(9 \%)$ & 0 & 0 \\
\hline Paresthesia & $1(3 \%)$ & $2(14 \%)$ & $3(17 \%)$ & $6(27 \%)$ & 0 & 0 \\
\hline Vision problems & 0 & 0 & 0 & 0 & 0 & 0 \\
\hline Cognitive difficulties & 0 & 0 & 0 & 0 & 0 & 0 \\
\hline Discomfort at injection site and/or lumbar region & 0 & $2(14 \%)$ & $2(11 \%)$ & $7(32 \%)$ & $2(33 \%)$ & $1(20 \%)$ \\
\hline Tremor & 0 & 0 & 0 & 0 & 0 & 0 \\
\hline No adverse events & $12(34 \%)$ & $3(21 \%)$ & $4(22 \%)$ & 0 & $2(33 \%)$ & $1(20 \%)$ \\
\hline
\end{tabular}

Note:- SIH indicates spontaneous intracranial hypotension; AC, arachnoid cyst; PC, pineal cyst; IIH, idiopathic intracranial hypertension; cHC, communicating hydrocephalus.

${ }^{a}$ Data are presented as No. of individuals (percentage in parentheses). 
ture studies, the effects of lower doses of gadobutrol should be explored. Additionally, other gadolinium-based contrast agents might be examined.

Another limitation is that the study included a high proportion of individuals with symptoms similar those reported after intrathecal gadobutrol. The patient selection most likely affected the symptom profile we also registered at time points after intrathecal injections.

\section{CONCLUSIONS}

This study showed intrathecal administration of gadobutrol for gMRI to be safe and feasible. We cannot, with certainty, conclude whether nonserious adverse effects such as headache and nausea were caused by gadobutrol, iohexanol, the lumbar puncture, or the diagnosis.

Disclosures: Svein Are Sirirud Vatnehol—UNRELATED: Payment for Lectures Including Service on Speakers Bureaus: Norwegian Medical Association, Comments: MRI safety lecture for radiologists in training.

\section{REFERENCES}

1. Iliff JJ, Wang M, Liao Y, et al. A paravascular pathway facilitates CSF flow through the brain parenchyma and the clearance of interstitial solutes, including amyloid $\boldsymbol{\beta}$. Sci Transl Med 2012;4:147ra111 CrossRef Medline

2. Rasmussen MK, Mestre $H$, Nedergaard $M$. The glymphatic pathway in neurological disorders. Lancet Neurol 2018;17:1016-24 CrossRef Medline

3. Iliff JJ, Lee H, Yu M, et al. Brain-wide pathway for waste clearance captured by contrast-enhanced MRI. J Clin Invest 2013;123:1299309 CrossRef Medline

4. Yang L, Kress BT, Weber HJ, et al. Evaluating glymphatic pathway function utilizing clinically relevant intrathecal infusion of CSF tracer. J Transl Med 2013;11:107 CrossRef Medline

5. Ringstad G, Valnes LM, Dale AM, et al. Brain-wide glymphatic enhancement and clearance in humans assessed with MRI. JCI Insight 2018;3 CrossRef Medline

6. Ringstad G, Vatnehol SA, Eide PK. Glymphatic MRI in idiopathic normal pressure hydrocephalus. Brain 2017;140:2691-705 CrossRef Medline

7. Eide PK, Ringstad G. Delayed clearance of cerebrospinal fluid tracer from entorhinal cortex in idiopathic normal pressure hydrocephalus: a glymphatic magnetic resonance imaging study. J Cereb Blood Flow Metab 2018 Feb 27:271678X18760974. [Epub ahead of print] CrossRef Medline

8. Louveau A, Smirnov I, Keyes TJ, et al. Structural and functional features of central nervous system lymphatic vessels. Nature 2015; 523:337-41 CrossRef Medline

9. Aspelund A, Antila S, Proulx ST, et al. A dural lymphatic vascular system that drains brain interstitial fluid and macromolecules. $J$ Exp Med 2015;212:991-99 CrossRef Medline

10. Eide PK, Vatnehol SA, Emblem KE, et al. Magnetic resonance imaging provides evidence of glymphatic drainage from human brain to cervical lymph nodes. Sci Rep 2018;8:7194 CrossRef Medline

11. Kanda T, Ishii K, Kawaguchi H, et al. High signal intensity in the dentate nucleus and globus pallidus on unenhanced T1-weighted MR images: relationship with increasing cumulative dose of a gadolinium-based contrast material. Radiology 2014;270:834-41 CrossRef Medline

12. Gulani V, Calamante F, Shellock FG, et al; International Society for Magnetic Resonance in Medicine. Gadolinium deposition in the brain: summary of evidence and recommendations. Lancet Neurol 2017;16:564-70 CrossRef Medline

13. Radbruch A, Haase R, Kieslich PJ, et al. No signal intensity increase in the dentate nucleus on unenhanced T1-weighted MR images af- ter more than 20 serial injections of macrocyclic gadolinium-based contrast agents. Radiology 2017;282:699-707 CrossRef Medline

14. Berger F, Kubik-Huch RA, Niemann T, et al. Gadolinium distribution in cerebrospinal fluid after administration of a gadoliniumbased MR contrast agent in humans. Radiology 2018;288:703-09 CrossRef Medline

15. Nehra AK, McDonald RJ, Bluhm AM, et al. Accumulation of gadolinium in human cerebrospinal fluid after gadobutrol-enhanced MR imaging: a prospective observational cohort study. Radiology 2018;288:416-23 CrossRef Medline

16. Jost G, Frenzel T, Lohrke J, et al. Penetration and distribution of gadolinium-based contrast agents into the cerebrospinal fluid in healthy rats: a potential pathway of entry into the brain tissue. Eur Radiol 2017;27:2877-85 CrossRef Medline

17. Eide PK, Pripp AH, Ringstad GA. Magnetic resonance imaging biomarkers indicate a central venous hypertension syndrome in patients with symptomatic pineal cysts. J Neurol Sci 2016;363:207-16 CrossRef Medline

18. Pradilla G, Jallo G. Arachnoid cysts: case series and review of the literature. Neurosurg Focus 2007;22:E7 Medline

19. Akbar JJ, Luetmer PH, Schwartz KM, et al. The role of MR myelography with intrathecal gadolinium in localization of spinal CSF leaks in patients with spontaneous intracranial hypotension. AJNR Am J Neuroradiol 2012;33:535-40 CrossRef Medline

20. Selcuk H, Albayram S, Ozer H, et al. Intrathecal gadolinium-enhanced MR cisternography in the evaluation of CSF leakage. AJNR Am J Neuroradiol 2010;31:71-75 CrossRef Medline

21. Tali ET, Ercan N, Kaymaz M, et al. Intrathecal gadolinium (gadopentetate dimeglumine)-enhanced MR cisternography used to determine potential communication between the cerebrospinal fluid pathways and intracranial arachnoid cysts. Neuroradiology 2004;46: 744-54 CrossRef Medline

22. Algin O, Hakyemez B, Ocakoğlu G, et al. MR cisternography: is it useful in the diagnosis of normal-pressure hydrocephalus and the selection of "good shunt responders"? Diagn Interv Radiol 2011;17: 105-11 CrossRef Medline

23. Nacar Dogan S, Kizilkilic O, Kocak B, et al. Intrathecal gadoliniumenhanced MR cisternography in patients with otorhinorrhea: 10year experience of a tertiary referral center. Neuroradiology 2018;60: 471-77 CrossRef Medline

24. Aydin K, Guven K, Sencer S, et al. MRI cisternography with gadolinium-containing contrast medium: its role, advantages and limitations in the investigation of rhinorrhoea. Neuroradiology 2004;46: 75-80 CrossRef Medline

25. Aydin K, Terzibasioglu E, Sencer S, et al. Localization of cerebrospinal fluid leaks by gadolinium-enhanced magnetic resonance cisternography: a 5-year single-center experience. Neurosurgery 2008;62:584-89; discussion 584-89 CrossRef Medline

26. Reiche W, Komenda Y, Schick B, et al. MR cisternography after intrathecal Gd-DTPA application. Eur Radiol 2002;12:2943-49 Medline

27. Skalpe IO, Tang GJ. Magnetic resonance imaging contrast media in the subarachnoid space: a comparison between gadodiamide injection and gadopentetate dimeglumine in an experimental study in pigs. Invest Radiol 1997;32:140-48 CrossRef Medline

28. Jinkins JR, Rudwan M, Krumina G, et al. Intrathecal gadoliniumenhanced MR cisternography in the evaluation of clinically suspected cerebrospinal fluid rhinorrhea in humans: early experience. Radiology 2002;222:555-59 CrossRef Medline

29. Tali ET, Ercan N, Krumina G, et al. Intrathecal gadolinium (gadopentetate dimeglumine) enhanced magnetic resonance myelography and cisternography: results of a multicenter study. Invest Radiol 2002;37:152-59 CrossRef Medline

30. Ray DE, Cavanagh JB, Nolan CC, et al. Neurotoxic effects of gadopentetate dimeglumine: behavioral disturbance and morphology after intracerebroventricular injection in rats. AJNR Am J Neuroradiol 1996;17:365-73 Medline

31. Li L, Gao FQ, Zhang B, et al. Overdosage of intrathecal gadolinium 
and neurological response. Clin Radiol 2008;63:1063-68 CrossRef Medline

32. Park KW, Im SB, Kim BT, et al. Neurotoxic manifestations of an overdose intrathecal injection of gadopentetate dimeglumine. $J \mathrm{Ko}-$ rean Med Sci 2010;25:505-08 CrossRef Medline

33. Arlt S, Cepek L, Rustenbeck HH, et al. Gadolinium encephalopathy due to accidental intrathecal administration of gadopentetate dimeglumine. J Neurol 2007;254:810-12 CrossRef Medline

34. Reeves C, Galang E, Padalia R, et al. Intrathecal injection of gadobutrol: a tale of caution. J Pain Palliat Care Pharmacother 2017; 31:139-43 CrossRef Medline

35. Palmers $\mathrm{Y}, \mathrm{Kuhn}$ FP, Petersen D, et al. Comparison in myelography between iodixanol 270 and $320 \mathrm{mgI} / \mathrm{ml}$ and iotrolan $300 \mathrm{mgI} / \mathrm{ml}$ : a multicentre, randomised, parallel-group, double-blind, phase III trial. Eur Radiol 2002;12:686-91 CrossRef Medline

36. Watts R, Steinklein JM, Waldman L, et al. Measuring glymphatic flow in man using quantitative contrast-enhanced MRI. AJNR Am J Neuroradiol 2019;40:648-51 CrossRef Medline 